\title{
Development of the Paris-Erdogan model for the quantitative evaluation of the wear resistance of materials under dynamic contact with a discrete liquid-drop flow
}

\author{
Valery N. Varavka*, Oleg V. Kudryakov, Natalia I. Bronnikova, Igor Yu. Zabiyaka, \\ Vladilen $V$. Rubanov \\ Don State Technical University, Material Sciences and Technology Department, 344000 Rostov-on- \\ Don Gagarin sq. 1, Russia
}

\begin{abstract}
The known fatigue model of Paris-Erdogan was first used for conditions of multi-cycle water-drop impacts with a metallic surface. The model is supplemented by the structure-dependent characteristics of the material. Experimental data providing correctness of model application is presented. The applied problem of quantitative evaluation of the material durability in the conditions of the droplet impact and comparison of materials of different structural classes was solved in the work without costly bench tests.
\end{abstract}

The problem of erosion wear and fracture of metal with multiple high-speed impacts with liquid droplets remains up to the present day for the turbine, compressor, extraction equipment operating in the conditions of condensate formation. The solution of the problem is complicated by the multifactority of the phenomenon, when at various stages of wear the various damaging factors play a dominant role: cavitation (hydrodynamic and bubbly), fatigue, corrosion. There is no general universal theory of droplet impingement erosion at this time. In this paper, a local problem was posed, based on the fatigue approach. The computational and analytical basis for determining the material's resistance to erosion wear under conditions of a multi-cycle shock-drop loading was conducted. A similar problem has already been solved by us in $[1,2]$ for such a highly plastic alloy as austenitic steel, which erodes with the formation of fatigue porosity by the mechanism of percolation. However, for such a high-strength alloy as martensitic steel, this model is not applicable.

The experimental base of the research was made by the data of testing samples on the unique erosion test bench «Erosion-M» (MPEI University, Moscow). In the vacuum working chamber of the test bench, a vertical monodisperse water-droplet flow is generated, simulating a condensate. The radius of the droplets is adjustable within $R_{0}=0.01 \ldots 0.6 \mathrm{~mm}$. A sample measuring $\varnothing 25 \times 8 \mathrm{~mm}$ moves around the circumference in a horizontal plane, simulating the turbine blade, compressor, etc. Impacts of the sample surface with a falling drop occur at a frequency of $60 \ldots 167 \mathrm{~Hz}$ at speeds $V_{0}=150 \ldots 613 \mathrm{~m} / \mathrm{s}$. The

\footnotetext{
* Corresponding author: varavkavn@gmail.com
} 
software of the test bench automatically determines the number of drip impacts (at the point of the sample surface) and the erodent-water consumption $m\left(\mathrm{~kg} / \mathrm{m}^{2}\right)$ during the test.

In the work we used samples of steel $20 \mathrm{Cr} 13$ (AISI 420) with a martensitic structure (Fig. 1a). In this steel martensite is formed during quenching in air, so samples with a martensitic structure used in the study were not subjected to tempering. The set of values of the mechanical properties required in the model calculations for such a steel: $\sigma_{t s}=1165 \mathrm{MPa}$; $H V=4170 \mathrm{MPa} ; K_{I C}=32 \mathrm{MPa} \cdot \mathrm{m}^{1 / 2}$.

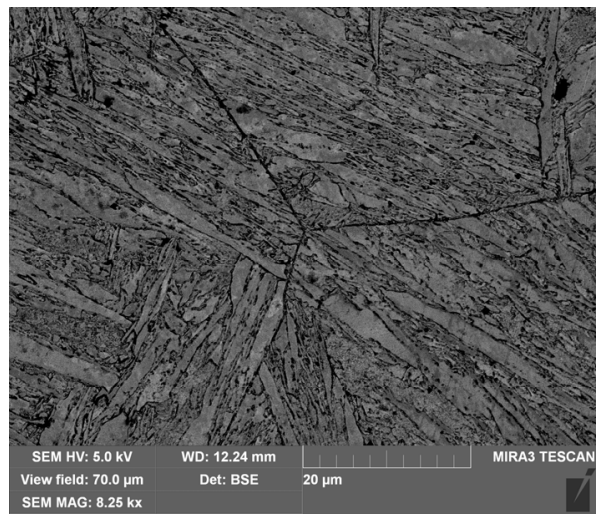

$\mathrm{a}$

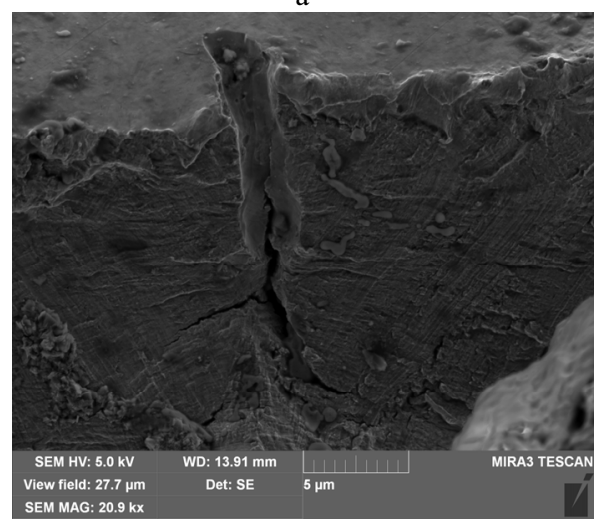

c

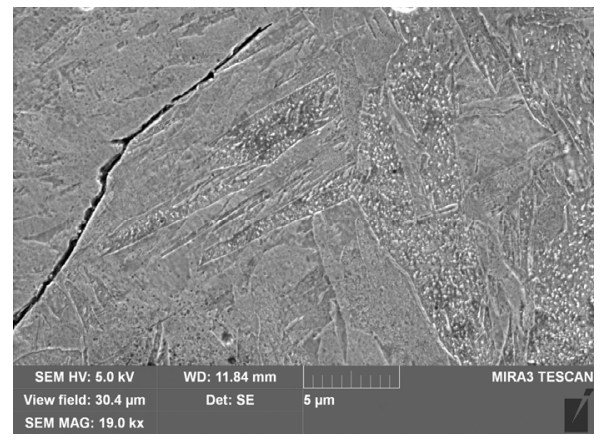

b

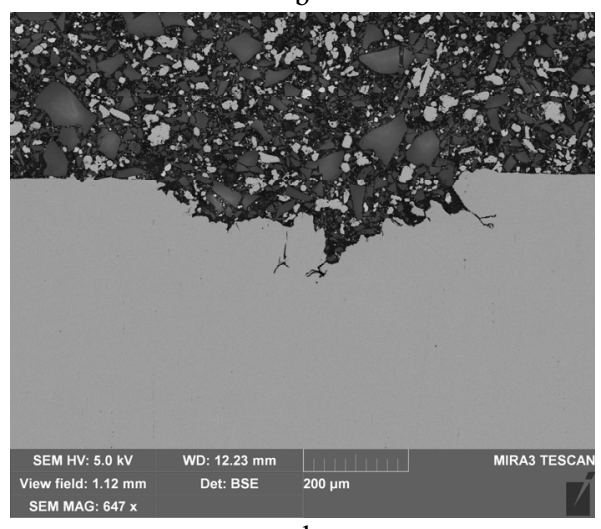

d

Fig. 1. The microstructure of steel $20 \mathrm{Cr} 13$ and the morphology of its droplet impingement fracture (SEM): $a$ - the initial microstructure; $b$ - surface fatigue crack; $c$ - morphology of the walls of the erosion crater and surface fatigue cracks; $d$ - branching of cracks.

In steel samples with high strength both the formation of primary erosion craters (Fig. 1c) and further development of wear (Fig. 1g) occurs by the generation and development of brittle cracks. This is indicated by the facet (smooth) relief of the crater's wall and the venous pattern characteristic of brittle cracks (Fig. 1c). The kinetics of wear begins with the initiation of a surface crack directed deep into the metal perpendicular to the surface (Fig. 1b, c). After reaching the critical size, the crack propagation is sharply accelerated and the wear particle is crushed to form the primary erosion crater. The process of development of wear, consisting in the expansion and deepening of primary craters, as well as in their fusion, develops along a similar mechanism for the initiation and expansion of brittle cracks perpendicular to the surface of the crater. At a certain stage, the cracks undergo branching (Fig. 1c, d), that is, the formation of cracks of the second order (new branches whose direction of development differs from the direction of growth of the primary crack). In the 
case of a droplet impact, branching, mainly due to the hydrodynamics of the collision: at the initial moment of the collision, when the drop is compressed and the reflected shock wave is formed, the pressure vector is directed perpendicular to the surface; then, when the cavitation cavity collapses in a drop, accompanied by the reactive spreading of the liquid along the metal surface, the pressure vector changes its direction, being located at an angle to the surface $[3,4]$. In the future, the kinetics of development of branching cracks is directed toward the fusion of their second-order branches with neighboring cracks, which determines the boundary of the wear particles with their subsequent separation (chipping).

Anti-erosion properties of material in the case of a droplet impingement impacts are usually characterized by the duration of the incubation period of wear $m_{0}$, when the loss of material mass is not yet detected [5-7]. Proceeding from this, the occurrence of wear in the martensitic structure corresponding to the instant $m_{0}$ is determined by the critical value of the size of the fragile crack formed $l_{C}$, after which the wear process develops in the form of loss of sample mass. In this case, the value of $m_{0}$ can have different ways of expressing: the number of the droplet impacts, exposure time (duration of the droplet impingement impacts in min, hour, day, etc.), mass or volume of expended erodent per unit surface area of the sample $\left(\mathrm{kg} / \mathrm{m}^{2}, \mathrm{~m}^{3} / \mathrm{m}^{2}\right)$, etc. When carrying out bench tests, all these dimensions are easily converted into each other, since they characterize the same value. In the present paper, for the characterization of $m_{0}$, we shall use the number of drops of the erodent (water) falling into one point of the sample surface. In this case, each impact is equivalent to an independent loading cycle of the steel sample, which allows us to use the approaches of fatigue theories for calculations.

In the general case, fatigue theory usually considers three stages of the fracture process in the form of a kinetic diagram of fatigue failure (Fig. 2).

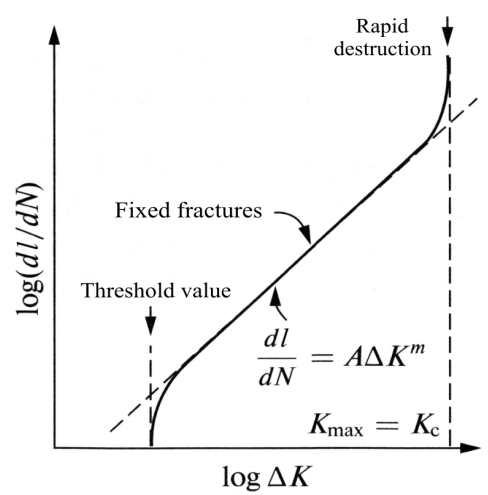

Fig. 2. The growth rate of the fatigue crack in the material containing the initial crack [9, p. 184]

Having originated and reaching a certain threshold value $l_{0}$, the length of the fatigue crack stably increases with acceleration, until it reaches the critical size $l_{C}$, which causes rapid destruction. One of the most widely used empirical models of the distribution of fatigue cracks is the Paris-Erdogan model [8]. It describes the stable growth of a fatigue crack of length $l$ in the form of the Paris equation:

$$
\frac{d l}{d N}=A \cdot \Delta K^{m}
$$

where $N$-number of loading cycles; $A$ and $m$ are the empirical constants of the material.

The magnitude of the stress concentration factor $K$ is generally determined by the value of the stress $\sigma$ acting in the material and the crack size $l$ : 


$$
K_{\text {max }}=\sigma_{\text {max }} \sqrt{\pi \cdot l} ; \quad K_{\text {min }}=\sigma_{\text {min }} \sqrt{\pi \cdot l} \text { для } \sigma_{\min }>0 \text { и } K_{\text {min }}=0 \text { для } \sigma_{\min } \leq 0
$$

The value of $\Delta K$ is determined by the expression (3) with allowance for the conditions (2):

$$
\Delta K=K_{\max }-K_{\min }=\Delta \sigma \cdot \sqrt{\pi \cdot l}
$$

Depending on the time, the value of $\Delta K$ gradually increases (at a constant load), since the length of the crack increases. The increment of the crack in one cycle $d l / d N$ increases with increasing $\Delta K$ in accordance with the dependence shown in Fig. 2. Let us consider the value of $\Delta K$ as applied to the droplet impingement impacts.

It was shown in $[1,10]$ that when a liquid drop collides with a metal surface, the stress $\sigma$ is distributed over the surface in time $\tau$ in accordance with the dependence shown in Fig. 3. The value of $\sigma$ is expressed in relative units $\rho_{0} \cdot c_{0} \cdot V_{0}$, called the hydro shock approximation. Time $\tau$ also has a relative scale, where $\rho_{0}$ is the density of the liquid, and $c_{0}$ is the velocity of sound in the liquid under normal conditions. Fig. 3 also shows the stress values adopted in the theory of fatigue, in particular in the Paris-Erdogan theory (maximum $\sigma_{\max }$, minimum $\sigma_{\min }$, mean $\sigma_{m}$, etc.). However, they require refinement for their use in the Paris equation. The essence of the refinement is that Fig. 3 shows the stress variation during a single impact time, and the Paris equation is used for multi-cycle loading.

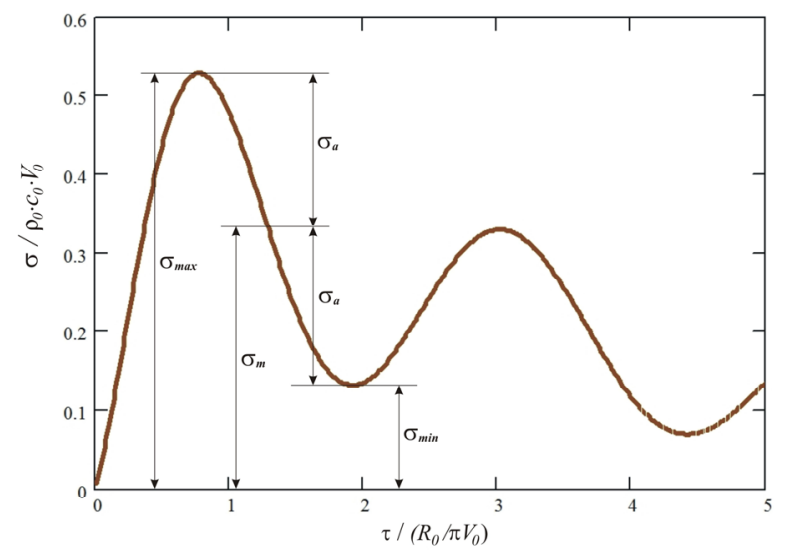

Fig. 3. Calculated parameters of the loading cycle for a single droplet impact.

Therefore, to use the calculated stress value (Fig. 3) in the Paris equation, it should be taken into account that in a single impact, $\sigma_{\min }$ tends to 0 with time. Then a single impact becomes a zero load cycle. In this case, the time between collisions falling into one point considerably exceeds the time of a single impact. From this it follows that under the considered conditions of the cyclic droplet impacts, in accordance with Fig. 3 in formula (3), it is necessary to take:

$$
\Delta \sigma=\sigma_{\max }=0,528 \cdot \rho_{0} \cdot c_{0} \cdot V_{0}
$$

Now the Paris equation (1) can be solved for the conditions of the droplet impingement erosion. If the empirical constants of material $A$ and $m$ are known, and, if the initial crack length $l_{0}$ and the final (critical) crack length $l_{C}$ at which catastrophic failure occurs can be determined or calculated, then the permissible number of cycles (droplet impacts) can be determined by integrating the Paris equation: 


$$
N_{C}=\int_{0}^{N_{C}} d N=\int_{l_{0}}^{l_{C}} \frac{d a}{A \cdot(\Delta K)^{m}}
$$

The value of $N_{C}$ obtained by integration, strictly speaking, is not the value of the incubation period of the droplet impingement erosion $m_{0}$, since it does not take into account the number of $N_{3}$ cycles necessary to form a crack of size $l_{0}$ :

$$
m_{0}=N_{3}+N_{C}
$$

To take into account $N_{3}$, we introduce the coefficient $\alpha_{0}$, which characterizes the ratio of the work of the nucleation of a crack, expressed by the number of cycles $N_{3}$, to the work of crack propagation, expressed by the number of cycles $N_{C}: \alpha_{0}=N_{3} / N_{C}$. Then, taking (6) into account:

$$
N_{C}=m_{0} /\left(1+\alpha_{0}\right) \text { and } N_{3}=m_{0} /\left(1+\alpha_{0}^{-1}\right)
$$

In expressions (6) and (7), all quantities are empirical for a given material. In the special scientific literature, theoretical dependencies connecting the values of these quantities could not be detected. However, it is clear that they are all structurally dependent. Therefore, for constructional materials of the same type of structural classes, in which the processes of nucleation and propagation of cracks develop along the same mechanisms, these values should be close. From this point of view, on the basis of our own experimental data (steel $20 \mathrm{Cr} 13$ ) and the data of a few sources (for example, steel 30CrMnSiNi2 in [11, p. 189]), the structural relationships presented in Table 1 can be proposed for the heat-hardenable alloyed structural steels. In Table 1 the durability $N$ is presented in the relative measurement with $N$ being the value corresponding to the maximum tempering temperature of 825-925 K $\left(N_{\text {rel. }}=1\right)$.

Table 1. Structural correlations of fracture parameters for the alloyed hypoeutectoid steel under cyclic impact loading.

\begin{tabular}{|c|c|c|c|c|c|}
\hline $\begin{array}{c}\text { Tempering } \\
\text { temperature } \\
\text { range }\end{array}$ & Structure & $\begin{array}{c}\text { The values of the } \\
\text { coefficient } \alpha_{0}\end{array}$ & $\begin{array}{c}\text { Average } \\
\text { value } \alpha_{0}\end{array}$ & $\begin{array}{c}\text { Value range } \\
N_{\text {rel. }}\end{array}$ & $\begin{array}{c}\text { Average } \\
\text { value } N_{\text {rel. }}\end{array}$ \\
\hline \hline $\begin{array}{c}325-525 \mathrm{~K} \\
\left(50-250^{\circ} \mathrm{C}\right)\end{array}$ & Martensit & $0,723-0,706$ & 0,715 & $1,06-1,30$ & 1,18 \\
\hline $\begin{array}{c}625-725 \mathrm{~K} \\
\left(350-450^{\circ} \mathrm{C}\right)\end{array}$ & Troostite & 0,375 & 0,375 & 1,23 & 1,23 \\
\hline $\begin{array}{c}825-925 \mathrm{~K} \\
\left(550-650^{\circ} \mathrm{C}\right)\end{array}$ & Sorbitol & $0,257-0,218$ & 0,24 & 1,0 & 1,0 \\
\hline
\end{tabular}

Among the parameters considered, the initial crack size $l_{0}$ remains an undefined quantity. With respect to the quantitative values of this value, there are different points of view. As $l_{0}$ can be used: the minimum crack length, determined theoretically by computational methods (for example, in fracture mechanics or in solid state physics), but not large enough to determine it experimentally; the minimum crack size determined by instrumental non-destructive methods (which can give significant discrepancies depending on the sensitivity threshold of the method or device); the ultimate crack length to which the product can be operated without the danger of catastrophic brittle failure (which irreversibly occurs when the critical length $l_{C}$ is reached). Without going into the discussion on this matter, we will use to determine the values of both $l_{0}$ and $l_{C}$ by the method of constructing the limit state diagram for a given material proposed in one of our papers [12]. In this case, the $l_{C}$ value can be sufficiently reliably monitored instrumentally (for example, by optical or electron microscopy). The obtained parameters of a surface brittle crack in the depth of a $20 \mathrm{Cr} 13$ steel sample with a martensitic structure were $l_{0}=0.548 \mu \mathrm{m}$ and 
$l_{C}=7.05 \mu \mathrm{m}$. The kinetics of the development of a fatigue crack in the interval $l_{0}-l_{C}$ is described by the Paris equation. The solution of the Paris equation (5) can be used to determine the number of loading cycles $m_{0}$ that the material is able to withstand before the formation of primary erosion wear craters. Moreover, the value of $m_{0}$ includes the number of load cycles necessary for the initiation of a crack, and is determined by the structure of the material.

The disadvantages of the discussed fatigue model include the presence in this equation of the empirical constants $A$ and $m$, which must be determined experimentally for each material. The values of $A$ and $m$ for various materials in the scientific literature are very small (see, for example, [13, p. 248-257]). Therefore, to ensure the accuracy of calculations within the framework of the design model, it is desirable to determine them experimentally for a specific material under study. For this purpose, a series of bench test for steel samples $20 \mathrm{Cr} 13$ with a martensitic structure was performed at the impact velocity $V_{0}=250 \mathrm{~m} / \mathrm{s}$ and the droplet diameter $D_{0}=1.1 \mathrm{~mm}$. In accordance with expression (4), such impacts will be characterized by stresses $\Delta \sigma=\sigma_{\max }=0,528 \cdot \rho_{0} \cdot c_{0} \cdot V_{0}=198 \mathrm{MPa}$, where for water $\rho_{0}=1000 \mathrm{~kg} / \mathrm{m}^{3}$, $c_{0}=1500 \mathrm{~m} / \mathrm{s}$. The duration of exposure at the erosion test bench was selected in such a way that the average size of the cracks formed was located in the indicated interval $l_{0}-l_{C}$. These average values of $l$ were 2,4 and $7 \mu \mathrm{m}$. The range of values of $l$ is given in Table 2 . The remaining values presented in Table 2 were obtained by calculation, including the number of loading cycles $N$ determined by the software of the test bench automatically by the exposure time $\tau$.

Table 2. The data of erosion tests of the samples on the determination of the parameters of the Paris equation at the impact velocity $V_{0}=250 \mathrm{~m} / \mathrm{s}$ and the droplet diameter $D_{0}=1.1 \mathrm{~mm}(\Delta \sigma=198 \mathrm{MPa})$.

\begin{tabular}{|c|c|c|c|c|c|c|}
\hline \multirow{2}{*}{$\begin{array}{c}\text { Sample } \\
\text { material }\end{array}$} & $\begin{array}{c}\text { Duration } \\
\tau, \text { min. }\end{array}$ & $\begin{array}{c}\text { Number of } \\
\text { loading cycles } N \\
\text { (the number of } \\
\text { drops that hit one } \\
\text { point in time } \tau)\end{array}$ & $\begin{array}{c}\text { Depth* of surface } \\
\text { crack } l, \mu \mathrm{m}\left(10^{-6}\right. \\
\mathrm{m})\end{array}$ & \multicolumn{3}{|c|}{$\begin{array}{c}\text { Estimated data } \\
\text { (for average values of } l \text { ) }\end{array}$} \\
\hline \hline & 37,75 & $6,31 \cdot 10^{3}$ & $0,55^{* *}$ & - & - & - \\
\cline { 2 - 7 } & 58,0 & $\begin{array}{c}9,7 \cdot 10^{3} \\
\left(\Delta N=3,39 \cdot 10^{3}\right)\end{array}$ & $2 \pm 0,5$ & $-9,229$ & 0,4962 & $-0,3044$ \\
\cline { 4 - 7 } $\begin{array}{c}20 \mathrm{Cr} 13 \\
\text { hardening } \\
\text { (martensite) }\end{array}$ & 75,0 & $\begin{array}{c}1,255 \cdot 10^{4} \\
\left(\Delta N=2,85 \cdot 10^{3}\right)\end{array}$ & $4 \pm 1,0$ & $-8,8526$ & 0,702 & $-0,154$ \\
\cline { 2 - 7 } & 90,5 & $\begin{array}{c}1,513 \cdot 10^{4} \\
\left(\Delta N=2,58 \cdot 10^{3}\right)\end{array}$ & $7 \pm 1,6$ & $-8,5488$ & 0,928 & $-0,0323$ \\
\hline
\end{tabular}

* - scanning electron microscopy;

** - the calculated value of the initial length of the fatigue crack in martensite $l_{0}$, taken as the crack germ

To determine the parameters $A$ and $m$, the power Paris equation (1) must be linearized by logarithm, after which it takes the form:

$$
\lg (\Delta l / \Delta N)=\lg A+m \cdot \lg (\Delta K)
$$

All calculated values included in the linearized Paris equation are given in Table 2, with the exception of $\lg A$ and $m$, which must be determined. The values of the parameters $\lg A$ and $m$ for steel $20 \mathrm{Cr} 13$ with a martensitic structure can be found either analytically from expression (8) from any two coordinates of points lying on the resulting straight line (8) or from a graph constructed from the data of Table 2 . The sought values of the parameters of the Paris equation for steel 20Cr13 were: $m=2,5$ и $A=3,403 \cdot 10^{-9} \mathrm{~m} /$ cycle.

Concerning the correspondence between the values of $l_{0}=0.55 \mu \mathrm{m}$ and $N_{3}=6.31 \times 10^{3}$ cycles, given in Table 2, some explanations should be made. The value of $N_{3}$ is obtained 
from the relations (7) with the values: $\alpha_{0}=0.715$ for the martensite structure (see Table 1) and $m_{0}=1.513 \cdot 10^{4}$ cycles - the experimental value obtained for bench tests (since the calculated value $l_{C}=7.05 \mu \mathrm{m}$ practically coincides with the value $l=7 \mu \mathrm{m}$ in the table, then we assume that this value of $l$ corresponds to $m_{0}$ ).

Knowing now the values of the parameters $A$ and $m$ of the Paris equation for the steel $20 \mathrm{Cr} 13$ with a martensitic structure, obtained experimentally, and also knowing the values of $l_{0}$ and $l_{C}$, calculated earlier, we can use the expression (5) to determine the calculatedexperimental value $N_{C}=8.82 \cdot 10^{3}$ cycles. Checking the relations (7) using the experimental value $m_{0}=1,513 \cdot 10^{4}$ cycles and $\alpha_{0}=0,715$ gives an almost exact coincidence with the calculation: $N_{C}=m_{0} /\left(1+\alpha_{0}\right)=8,822 \cdot 10^{3}$ cycles.

Thus, the calculated and analytical model of wear during the droplet impingement erosion is considered based on the Paris equation from the fatigue theory of Paris-Erdogan. The maximum number of loading cycles is calculated (the number of impacts of drops falling into one point) that the material can withstand before the start of wear formation. This moment is determined by the critical value of $l_{C}$. In this case, the parameters of the Paris equation for the material, strictly speaking, must be determined from the experiment. For a qualitative comparative evaluation it is permissible to use the known typical values of the parameters $A$ and $m$, which are given in the reference sources, however, not all types of materials have been studied from the point of view of using the Paris equation for them. Therefore, the comparison of materials and the use of typical values for them should be carried out with the obligatory consideration of structural features. The result of the calculation determines the resistance of the material to erosion wear $m_{0}$. The developed model allows using a minimal set of mechanical properties of the material and typical values of the structurally dependent parameters, without costly erosion bench testing. Laboratory or bench diagnosis of the material can be recommended only as an experimental verification of the calculated results.

The reported study was funded by RFBR according to the research project no. 18-08-00546.

\section{References}

1. V. Varavka, O. Kudryakov, J. Friction and Wear, 36 (1), 71 (2015)

2. V. Varavka, O. Kudryakov, J. Friction and Wear, 36 (2), 153 (2015)

3. Chizhov, A. Shmidt, Tech. Phys., 45, 1529 (2000)

4. K. Haller, Y. Ventikos, D. Poulikakos, P. Monkewitz, J. Appl. Phys., 92, 2821 (2002)

5. L. Seleznev, V. Ryzhenkov, Therm. Eng., 52 (4), 61 (2005)

6. V. Ryzhenkov, G. Kachalin, A. Mednikov, Al. Mednikov, O. Kudryakov, V. Varavka, Nadezhn. Bezopasn. Energ., 16 (1), 67 (2012)

7. Mednikov, V. Ryzhenkov, L. Seleznev, A. Lebedeva, Therm. Eng. 59 (5), 414 (2012)

8. P. Paris, F. Erdogan, Trans. ASME, J. Basic Engng., 15, 528 (1963)

9. M. Ashby, D. Jones, Engineering Materials, 2nd. ed. (Elsevier, Oxford, 1996)

10. O. Kudryakov, V. Varavka, J. Surf. Investig. X-ray, Synchr. and Neutr. Techn., 9 (1), 203 (2015)

11. S. Kovchik, E. Morozov, Mechanics of failure and strength of materials, v.3 (Naukova Dumka, Kiev, 1988)

12. V. Varavka, O. Kudryakov, I. Zabiyaka, A. Shapovalova, MATEC Web Conf, 132, 03004 (2017)

13. V. Goritsky, Diagnostics of metals (Metallurgizdat, Moscow, 2004) 